\title{
PHENOTYPIC VARIATION AND GENOTYPIC DIVERSITY IN A PLANKTONIC POPULATION OF THE TOXIGENIC MARINE DINOFLAGELLATE ALEXANDRIUM TAMARENSE (DINOPHYCEAE) ${ }^{1}$
}

\author{
Tilman J. Alpermann ${ }^{2}$ \\ LOEWE Biodiversity and Climate Research Centre (BiK-F), Tropical Marine Ecosystems Group, Senckenberganlage 25, \\ D-60325 Frankfurt a.M., Germany \\ Ecological Chemistry Section, Alfred Wegener Institute for Polar and Marine Research, Am Handelshafen 12, \\ D-27570 Bremerhaven, Germany \\ Urban Tillmann
}

Ecological Chemistry Section, Alfred Wegener Institute for Polar and Marine Research, Am Handelshafen 12, D-27570 Bremerhaven, Germany

Bánk Beszteri

Department of Microbiology, Oregon State University, 220 Nash Hall, Corvallis, Oregon 97331, USA Scientific Computing Group, Alfred Wegener Institute for Polar and Marine Research, Am Handelshafen 12, D-27570 Bremerhaven, Germany

Allan D. Cembella and Uwe John

Ecological Chemistry Section, Alfred Wegener Institute for Polar and Marine Research, Am Handelshafen 12, D-27570 Bremerhaven, Germany

Multiple clonal isolates from a geographic population of Alexandrium tamarense (M. Lebour) Balech from the North Sea exhibited high genotypic and phenotypic variation. Genetic heterogeneity was such that no clonal lineage was repeatedly sampled according to genotypic markers specified by amplified fragment length polymorphism (AFLP) and microsatellites. Subsampling of genotypic data from both markers showed that ordination of individuals by pair-wise genetic dissimilarity indices was more reliable by AFLP (482 biallelic loci) than by microsatellites (18 loci). However, resulting patterns of pair-wise genetic similarities from both markers were significantly correlated (Mantel test $\boldsymbol{P}<\mathbf{0 . 0 0 5}$ ). The composition of neurotoxins associated with paralytic shellfish poisoning (PSP) was also highly diverse among these isolates and allowed clustering of toxin phenotypes based on prevalence of individual toxins. Correlation analysis of pair-wise relatedness of individual clones according to PSP-toxin profiles and both genotypic characters failed to yield close associations. The expression of allelochemical properties against the cryptophyte Rhodomonas salina (Wisłouch) D. R. A. Hill et Wetherbee

\footnotetext{
${ }^{1}$ Received 21 November 2008. Accepted 27 July 2009.

${ }^{2}$ Author for correspondence: e-mail talpermann@meeresforschung.de.
}

and the predatory dinoflagellate Oxyrrhis marina Dujard. manifested population-wide variation of responses in the target species, from no visible effect to complete lysis of target cells. Whereas the high genotypic variation indicates high potential for adaptability of the population, we interpret the wide phenotypic variation as evidence for lack of strong selective pressure on respective phenotypic traits at the time the population was sampled. Population markers as applied here may elucidate the ecological significance of respective traits when followed under variable environmental conditions, thereby revealing how variation is maintained within populations.

Key index words: AFLP; Alexandrium tamarense; allelopathy; dinoflagellate population; genotypic diversity; microsatellites; paralytic shellfish poisoning toxins; phenotypic variation

Abbreviations: AFLP, amplified fragment length polymorphism; PSP, paralytic shellfish poisoning

Marine microalgae in coastal regions live in dynamic environments characterized by frequent and often sudden changes in ambient conditions. Abiotic parameters, such as turbidity, light intensity, salinity, and nutrient availability, can vary dramatically within 
submeter spatial scales in the water column. Additionally, biotic interactions among microalgae and potential grazers or pathogens are major determinants that influence the population growth of particular microalgal species (Smayda 1997, Tillmann 2004). If changes in ambient conditions reduce growth, microalgal populations can secure their persistence or eventually restore net growth in two principally different ways. One mechanism is for all individuals of the respective population to express a common phenotypic plasticity, allowing them to acclimate physiologically to new conditions. The other mechanism to cope with altered ambient conditions is by expression of population-wide phenotypic variation, enabling growth of those individuals that express the relatively better-adapted phenotypes for the respective environmental conditions. Physiological acclimation, with all individuals growing equally well under changing ambient conditions, would tend to result in more or less uniform populations for the respective phenotypes, whereas adaptation of populations would lead to phenotypic diversity due to balancing selection, especially if changes in determining environmental variables (forcing functions) occur frequently. The amount and patterns of intraspecific phenotypic variation are therefore crucial factors determining the ecological and microevolutionary fate of microalgal species and populations.

Underlying genetic variation, the basis for observed phenotypic variation, is assumed to reflect the ability of a population to adapt to changing environments (Fisher 1930, Barrett and Schluter 2008). Several studies of marine microalgae, particularly of diatoms (see Medlin et al. 2000), have revealed a high degree of cryptic variation, both phenotypic and genotypic, within microalgal species and even within single geographically defined populations. In some cases, microalgal species showing large variation were later attributed to species complexes [e.g., Skeletonema costatum (Gallagher 1980, 1982, Sarno et al. 2005, Kooistra et al. 2008) and A. tamarense (Scholin et al. 1995)]. Most studies of intraspecific variation within microalgal species or populations, however, have concentrated either on phenotypic or genotypic variation, or did not specifically compare variation at the population or species level. This is very unfortunate, since studies that integrate information on diversity and populationwide distribution of key phenotypic traits with that obtained by fine-scale genotypic markers are promising approaches to tackle questions on the evolutionary ecology of planktonic microalgae.

Such an integrative approach was chosen in this study to investigate population characteristics of the toxic marine dinoflagellate $A$. tamarense. This dinoflagellate can form harmful algal blooms (HABs), particularly along temperate and subtropical coasts. The "A. tamarense species complex" includes different morphotypes that were assigned species status before the advent of molecular genetic markers (Balech 1995 and references therein). According to LSU rDNA sequences, members of the A. tamarense species complex fall into ribotypes of geographically distinct origin and distribution, each containing one or more different morphotypes (Scholin et al. 1994, John et al. 2003). In addition to their genetic differentiation, ribotypes differ phenotypically by the presence or absence of neurotoxins associated with PSP (Scholin et al. 1994, John et al. 2003, Lilly et al. 2007). The PSP toxins comprise $>20$ naturally occurring derivatives of the tetrahydropurine saxitoxin that may be produced among toxigenic strains, although typically the toxin profile is dominated by few analogs within a given strain. The ecological and evolutionary significance of PSP toxins to the producing dinoflagellate is not well understood, but toxigenic clonal isolates of the same ribotypes may produce markedly different relative amounts of various saxitoxin derivatives (Cembella 2003). The resulting PSP-toxin composition within a clonal isolate is rather stable under a range of environmental conditions (Hall 1982, Boyer et al. 1987, Cembella et al. 1987, Ogata et al. 1987).

Variation in PSP toxins has been the focus of most previous studies (Hall 1982, Cembella et al. 1987, Anderson et al. 1994, Cembella and Destombe 1996, Ichimi et al. 2002) for comparison of regionally predominating toxin profiles or changes in toxin composition or cell content under different ambient conditions in culture. Consequently, only single strains or a few isolates derived from local populations have been studied, and these then were assumed to be characteristic of their geographic origin. However, an in-depth analysis of intrapopulation diversity of this intriguing phenotypic trait with a multitude of isolates is lacking. Such an analysis might provide important insights into the genetics of toxin production in Alexandrium.

Allelopathic interactions among microalgal species or allelochemical defense against grazing may have a major effect in determining which species attain bloom concentrations in a certain plankton community (Smayda 1997, Tillmann 2004). Almost all Alexandrium species tested contain strains known to express allelochemical properties, usually manifested as lytic or membrane-disruptive activity, against a wide spectrum of protistan target species (Tillmann et al. 2008). The potency against protists is dependent on susceptibility of the given target species, but capacity to elicit allelochemical activity also varies widely among strains of different Alexandrium species and within the same species among strains from different geographic origins (Tillmann and John 2002). In all cases, these allelochemical responses are apparently unrelated to the content of PSP toxins or other known biotoxins, such as the macrocyclic imine spirolides, which may be produced among Alexandrium strains (Tillmann and John 2002, Fistarol et al. 2004, Tillmann et al. 2007). 
Ribosomal DNA sequences have served well for grouping members of the A. tamarense species complex into regional ribotypes, but other genotypic markers with higher resolving power at the population level are needed to assess genotypic diversity within populations of established LSU ribotypes. AFLP (Vos et al. 1995) and microsatellites or simple sequence repeats (SSR) (Tautz and Renz 1984) are two such presumably neutral genetic markers widely used for assessment of genotypic diversification within and among populations. Although these markers have been previously applied to A. tamarense in studies on gene diversity (Nagai et al. 2004, Alpermann et al. 2006), population differentiation (Nagai et al. 2007), regional genotypic differentiation (John et al. 2004), and genome divergence (Alpermann et al. 2008), the extent of population-wide genotypic diversity as a common feature in a natural population of A. tamarense has not been evaluated before.

Our study simultaneously addressed phenotypic variation and genotypic diversity among clonal isolates from a single A. tamarense population. Here, our primary aim was to assess the degree to which different phenotypic and genotypic characters vary within one planktonic population from the Scottish east coast. Following from this, our second objective was to discover whether population-wide patterns that result from this variation by multivariate ordination are congruent for different characters or if certain AFLP loci are associated with phenotypic characteristics in the sampled population. The phenotypic markers we chose were profiles and cellular content of PSP toxins as well as allelochemical properties, which we assessed by a survey of a large number of clonal isolates derived from the same source population. For the characterization of the genotypic diversity in this natural population, we genotyped the isolates by multiallelic microsatellite (Nagai et al. 2004, Alpermann et al. 2006) and biallelic AFLP markers (Vos et al. 1995, John et al. 2004). This study provides the first detailed multiparameter evidence for high genotypic and phenotypic variation within a population of a marine dinoflagellate. The population-wide heterogeneities in phenotypic and genotypic traits apparent from this study provide important indicators for the ecological significance of specific characters for development of A. tamarense populations and blooms.

\section{MATERIALS AND METHODS}

Establishment and culture of clonal A. tamarense isolates. In May 2004, a natural population of A. tamarense was sampled from the North Sea coast of Scotland at $56^{\circ} 05^{\prime} 47^{\prime \prime} \mathrm{N}$ and $1^{\circ} 42^{\prime} 35^{\prime \prime} \mathrm{W}$. Phytoplankton were collected by repeated vertical hauls of a $20 \mu \mathrm{m}$ mesh plankton net (Hydrobios, Kiel, Germany) from $20 \mathrm{~m}$ depth to the surface. Utermöhl counts of Alexandrium spp. yielded an in situ concentration of $\sim 90$ cells $\cdot \mathrm{L}^{-1}$ based on estimates from net tows from the water column. Single A. tamarense cells were isolated from this sample under a stereomicroscope (M5A, Wild, Heerbrugg, Switzerland) by micropipette. The cells were transferred into individual wells of 96-well tissue culture plates (TPP, Trasadingen, Switzerland) containing $150 \mu \mathrm{L}$ of $\mathrm{K}$ medium (Keller et al. 1987), supplemented with selenite (Dahl et al. 1989), prepared from $0.2 \mu \mathrm{m}$ sterile-filtered natural Antarctic seawater diluted with seawater from the sampling location in a ratio of $1: 10$. Isolated cells were then incubated at $10^{\circ} \mathrm{C}$ under artificial light at a photon flux density of $100 \mu \mathrm{mol}$ photons $\cdot \mathrm{m}^{-2} \cdot \mathrm{s}^{-1}$ on a 16:8 light:dark (L:D) photocycle. After 3 to 4 weeks, unialgal isolates were transferred to 24-well tissue culture plates, each well containing $1.5 \mathrm{~mL}$ of $\mathrm{K}$ medium diluted 1:5 with Antarctic seawater and incubated at $15^{\circ} \mathrm{C}$ under the previous photoregime. Exponentially growing isolates were finally used as inoculum for batch cultures in polystyrene cell culture flasks each containing $50 \mathrm{~mL}$ of $\mathrm{K}$ medium and were maintained thereafter under the same conditions as described. From a total of $>100$ clonal isolates of $A$. tamarense, 88 clones were arbitrarily chosen to study the genotypic and phenotypic diversity and genetic structure within this natural population.

DNA extraction and ribotyping of clonal isolates. Freshly inoculated batch cultures $(800 \mathrm{~mL})$ of 88 clonal isolates of A. tamarense were treated with the antibiotics (Sigma, Munich, Germany) penicillin (final concentration $100 \mu \mathrm{g} \cdot \mathrm{mL}^{-1}$ ) and streptomycin (final concentration $25 \mu \mathrm{g} \cdot \mathrm{mL}^{-1}$ ) and harvested $\sim 3$ weeks later when they reached mid- to late-exponential growth phase $\left(3\right.$ to $8 \times 10^{3}$ cells $\left.\cdot \mathrm{mL}^{-1}\right)$ by gravity filtration over a $10 \mu \mathrm{m}$ polyethylene (Nitex 03-10/02, Sefar, Thal, Switzerland) mesh. The cells were resuspended and washed twice in $\sim 50 \mathrm{~mL}$ of filtered seawater and filtered again through the mesh. Finally, the cells were resuspended in $50 \mathrm{~mL}$ of filtered seawater and transferred to $50 \mathrm{~mL}$ conical centrifugation tubes and then centrifuged (Eppendorf, Hamburg, Germany, Centrifuge $5415 \mathrm{R}$ ) at $3,200 \mathrm{~g}$ for $15 \mathrm{~min}$. The supernatant was discarded, and the pellet was resuspended in $1.5 \mathrm{~mL}$ of filtered seawater and transferred to a $2 \mathrm{~mL}$ reaction tube. After microcentrifugation of the cell suspension at $16,000 \mathrm{~g}$ for $5 \mathrm{~min}$, the supernatant was removed, and the cell pellet was shock-frozen in liquid nitrogen and stored at $-20^{\circ} \mathrm{C}$ until DNA extraction.

For cell disruption, the frozen cell pellet was chilled in liquid nitrogen and homogenized twice at $20 \mathrm{~Hz}$ for $1 \mathrm{~min}$ in a mixer mill MM200 (Retsch, Haan, Germany). DNA was subsequently extracted with a DNeasy Plant Mini Kit or a DNeasy 96 Plant Kit (Qiagen, Hilden, Germany) according to the manufacturer's instructions. The purity and quantity of the DNA were checked using a NanoDrop ND-1000 UV-spectro-photometer (Peqlab, Erlangen, Germany), and the integrity of DNA fragments of a molecular weight of $\sim 20 \mathrm{~kb}$ was verified on a $0.8 \%$ agarose gel.

All isolates were confirmed to belong to Group I (Lilly et al. 2007) of the A. tamarense species complex (formerly North American ribotype) by sequencing of the D1-D2 LSU rDNA region (Scholin et al. 1994). Sequences were deposited in GenBank (accession numbers FJ404475 to FJ404562).

AFLP genotyping. Assessment of polymorphic loci was carried out according to the AFLP protocol of John et al. (2004) (see also for sequences of adapters in the ligation and primers in the preamplification reactions). Alexandrium DNA (240 ng) was digested for $15 \mathrm{~h}$ at $37^{\circ} \mathrm{C}$ in a $50 \mu \mathrm{L}$ digestion reaction mix containing $1 \mu \mathrm{L} E c o$ RI $\left(20 \mathrm{U} \cdot \mu \mathrm{L}^{-1}\right), 1 \mu \mathrm{L}$ MseI $\left(10 \mathrm{U} \cdot \mu \mathrm{L}^{-1}\right)$, $0.5 \mu \mathrm{L} \mathrm{BSA}$, and $5 \mu \mathrm{L}$ restriction buffer 2 (all reagents from New England BioLabs, Frankfurt am Main, Germany). Afterward, the enzymes were heat-inactivated at $65^{\circ} \mathrm{C}$ for $15 \mathrm{~min}$. The restriction mix $(17 \mu \mathrm{L})$ was added to $8 \mu \mathrm{L}$ of a ligation mix consisting of $2.5 \mu \mathrm{L}$ water, $1.7 \mu \mathrm{L}$ ATP $(10 \mathrm{mM}), 1 \mu \mathrm{L} \mathrm{EcoRI}$ adapter $\left(10 \mathrm{pmol} \cdot \mu \mathrm{L}^{-1}\right), 1 \mu \mathrm{L}$ MseI adapter $\left(50 \mathrm{pmol} \cdot \mu \mathrm{L}^{-1}\right)$, $0.8 \mu \mathrm{L}$ T4 ligase buffer, and $1 \mu \mathrm{L}$ T4 DNA ligase $\left(1 \mathrm{U} \cdot \mu \mathrm{L}^{-1}\right.$, GE Health Care Life Sciences, Munich, Germany). The mix was incubated for $9 \mathrm{~h}$ at $16^{\circ} \mathrm{C}$ and subsequently for $6 \mathrm{~h}$ at $21^{\circ} \mathrm{C}$. The ligation reaction was then stopped by heating for $10 \mathrm{~min}$ at $65^{\circ} \mathrm{C}$. The ligated DNA was diluted 1:5 in 0.1x Tris-EDTA 
TABle 1. Combinations of primers and their characteristics in the amplified fragment length polymorphism (AFLP) amplification reaction.

\begin{tabular}{lcccc}
\hline \hline Primer combination & EcoRI-Primer & Msel-Primer & Number of polymorphic loci & Mean number of present alleles $( \pm$ SD) \\
\hline 1 & EcoRI + AAG & MseI + CTA & 109 & $26.5( \pm 7.7)$ \\
2 & EcoRI + AGG & MseI + CCG & 117 & $23.2( \pm 7.7)$ \\
3 & EcoRI + AAG & MseI + CTT & 133 & $41.5( \pm 13.5)$ \\
4 & EcoRI + AGG & MseI + CCT & 123 & $34.5( \pm 10.5)$ \\
\hline
\end{tabular}

buffer, and $6.67 \mu \mathrm{L}$ of it was added to a PCR mix consisting of $8.33 \mu \mathrm{L}$ water, $0.33 \mu \mathrm{L} E c o \mathrm{RI}+\mathrm{A}$ primer $(10 \mu \mathrm{M}), 0.33 \mu \mathrm{L}$ MseI+C primer $(10 \mu \mathrm{M}), 2 \mu \mathrm{L}$ 10x Taq DNA polymerase buffer, $2 \mu \mathrm{L}$ dNTP-Mix (1 mM each), and $0.33 \mu \mathrm{L}$ HotMaster $^{\mathrm{TM}}$ Taq DNA Polymerase $\left(5 \mathrm{U} \cdot \mu \mathrm{L}^{-1}\right.$ ) (all PCR reagents from Eppendorf). This reaction mix was cycled 22 times for preamplification of the ligated DNA in a Mastercycler Gradient thermocycler (Eppendorf) at $94^{\circ} \mathrm{C}$ for $30 \mathrm{~s}$ (denaturation), $56^{\circ} \mathrm{C}$ for $30 \mathrm{~s}$ (annealing), and $72^{\circ} \mathrm{C}$ for $1 \mathrm{~min}$ (extension). The PCR products were diluted 1:10 in 0.1x Tris-EDTA buffer. The final selective amplification was carried out with the diluted reaction product of the preamplification reaction and four different combinations of selective primers in separate reactions, where each selective primer contained three selective bases (see Table 1). The amplification reaction mix contained $3.33 \mu \mathrm{L}$ of the diluted preamplification reaction product, $7.8 \mu \mathrm{L}$ of water, $1.33 \mu \mathrm{L} 10 \mathrm{x}$ Taq DNA polymerase buffer, $0.13 \mu \mathrm{L}$ dNTP-Mix (10 mM each), $0.4 \mu \mathrm{L}$ MseI amplification primer $\left(10 \mathrm{pmol} \cdot \mu \mathrm{L}^{-1}\right), 0.07 \mu \mathrm{L}$ of 6 -FAM labeled EcoRI amplification primer $\left(10 \mathrm{pmol} \cdot \mu \mathrm{L}^{-1}\right)$, and $0.27 \mu \mathrm{L}$ HotMasterTM Taq DNA Polymerase $\left(5 \mathrm{U} \cdot \mu \mathrm{L}^{-1}\right.$ ) (all PCR reagents from Eppendorf). Amplification by touchdown PCR was performed with an initial denaturation at $94^{\circ} \mathrm{C}$ for $30 \mathrm{~s}$ and a first cycle at $94^{\circ} \mathrm{C}$ for $30 \mathrm{~s}$ (denaturation), $65^{\circ} \mathrm{C}$ for $30 \mathrm{~s}$ (annealing), and $72^{\circ} \mathrm{C}$ for $60 \mathrm{~s}$ (extension). During the next 12 cycles, the annealing temperature was reduced by $0.8^{\circ} \mathrm{C}$ per cycle down to $56^{\circ} \mathrm{C}$, whereas the last 23 cycles were the same as described for preamplification. One microliter of the product of the amplification reaction in $15 \mu \mathrm{L} \mathrm{HiDi}^{\mathrm{TM}}$ formamide and $0.5 \mu \mathrm{L}$ of the size-marker GeneScan ${ }^{\mathrm{TM}}-500\left[\mathrm{ROX}^{\mathrm{TM}}\right.$ (both reagents from Applied Biosystems, Darmstadt, Germany) were sized by a capillary sequencer ABI 3130XL (Applied Biosystems). Sizing and scoring of AFLP fragments in a range from 100 to $500 \mathrm{bp}$ was carried out using GeneMapper ${ }^{\circledR} \mathrm{v} 4.0$ (Applied Biosystems) with a signal intensity threshold of " 250 " for binning and a threshold of " 50 " for scoring of AFLP loci. Signal intensity was normalized over all samples for binning and scoring.

Microsatellite genotyping. Eighteen previously characterized microsatellite loci (Nagai et al. 2004, Alpermann et al. 2006) were amplified from the same DNA templates of the 88 clonal A. tamarense isolates used for AFLP analysis, with specific primers developed for the A. tamarense North American ribotype (Table 2). The PCR conditions were as described in Alpermann et al. (2006). In brief, $20 \mu \mathrm{L}$ PCR reactions were run for each pair of specific primers containing 10-20 ng of DNA, $10 \mathrm{mM}$ Tris- $\mathrm{HCl}, 50 \mathrm{mM} \mathrm{KCl}, 1.5 \mathrm{mM} \mathrm{MgCl}_{2}, 0.2 \mathrm{mM}$ dNTPs, $0.1 \mu \mathrm{M}$ of each primer (except locus ATB1 with primer concentrations of $0.5 \mu \mathrm{M})$, and 1 unit of HotMaster ${ }^{\mathrm{TM}}$ Taq DNA Polymerase (Eppendorf). The PCR was performed either with a constant annealing temperature for 40 PCR cycles (only for locus ATB1) or as a touchdown PCR with 20 cycles, in which the annealing temperature was reduced by $0.3^{\circ} \mathrm{C}$ every cycle, followed by 25 cycles at constant annealing temperature (Table 2). One of the two primers in each PCR was $5^{\prime}$ terminally labeled with either 6-FAM, NED or HEX (Applied Biosystems). Sizing and scoring of microsatellite alleles were carried out using the software GeneMapper ${ }^{\circledR}$ v3.7 (Applied
TABle 2. Specifications, experimental parameters, and results of microsatellite loci for genotyping Alexandrium tamarense isolates.

\begin{tabular}{lcccc}
\hline \hline Locus & TD- $T_{\mathrm{a}}$ & $T_{\mathrm{a}}$ & $\begin{array}{c}\text { Number } \\
\text { of alleles }\end{array}$ & $\begin{array}{c}\text { Gene } \\
\text { diversity }(\hat{H})^{\mathrm{a}}\end{array}$ \\
\hline ATB1 $^{\mathrm{b}}$ & - & $53^{\circ} \mathrm{C}$ & 2 & 0.31 \\
ATB8 $^{\mathrm{b}}$ & $61^{\circ} \mathrm{C}$ & $54^{\circ} \mathrm{C}$ & 9 & 0.76 \\
ATD8 $^{\mathrm{b}}$ & $61^{\circ} \mathrm{C}$ & $54^{\circ} \mathrm{C}$ & 4 & 0.74 \\
ATF1 $^{\mathrm{b}}$ & $61^{\circ} \mathrm{C}$ & $54^{\circ} \mathrm{C}$ & 8 & 0.70 \\
ATF11 $^{\mathrm{b}}$ & $68.5^{\circ} \mathrm{C}$ & $61.5^{\circ} \mathrm{C}$ & 6 & 0.35 \\
ATG6 $^{\mathrm{b}}$ & $62.7^{\circ} \mathrm{C}$ & $55.7^{\circ} \mathrm{C}$ & 5 & 0.68 \\
Atama04 $^{\mathrm{c}}$ & $61^{\circ} \mathrm{C}$ & $54^{\circ} \mathrm{C}$ & 3 & 0.57 \\
Atama06 $^{\mathrm{c}}$ & $67^{\circ} \mathrm{C}$ & $60^{\circ} \mathrm{C}$ & 3 & 0.53 \\
Atama13 $^{\mathrm{c}}$ & $60^{\circ} \mathrm{C}$ & $53^{\circ} \mathrm{C}$ & 6 & 0.73 \\
Atama15 $^{\mathrm{c}}$ & $63^{\circ} \mathrm{C}$ & $56^{\circ} \mathrm{C}$ & 8 & 0.68 \\
Atama16 $^{\mathrm{c}}$ & $63^{\circ} \mathrm{C}$ & $56^{\circ} \mathrm{C}$ & 6 & 0.56 \\
Atama17 $^{\mathrm{c}}$ & $59^{\circ} \mathrm{C}$ & $52^{\circ} \mathrm{C}$ & 5 & 0.73 \\
Atama23 $^{\mathrm{c}}$ & $59^{\circ} \mathrm{C}$ & $52^{\circ} \mathrm{C}$ & 3 & 0.49 \\
Atama26 $^{\mathrm{c}}$ & $56^{\circ} \mathrm{C}$ & $49^{\circ} \mathrm{C}$ & 4 & 0.50 \\
Atama27 $^{\mathrm{c}}$ & $58^{\circ} \mathrm{C}$ & $51^{\circ} \mathrm{C}$ & 10 & 0.83 \\
Atama32 $^{\mathrm{c}}$ & $60^{\circ} \mathrm{C}$ & $53^{\circ} \mathrm{C}$ & 7 & 0.83 \\
Atama39 & $59^{\circ} \mathrm{C}$ & $52^{\circ} \mathrm{C}$ & 3 & 0.50 \\
Atama42 $^{\mathrm{c}}$ & $59^{\circ} \mathrm{C}$ & $52^{\circ} \mathrm{C}$ & 7 & 0.70 \\
\hline
\end{tabular}

TD- $T_{\mathrm{a}}$, annealing temperature of first cycle of touch-down PCR; $T_{\mathrm{a}}$, constant annealing temperature.

${ }^{\mathrm{a}}$ Nei (1987), ${ }^{\mathrm{b}}$ Alpermann et al. (2006), ${ }^{\mathrm{C}}$ Nagai et al. (2004).

Biosystems) after capillary electrophoresis as performed for AFLP amplicons.

Analysis of AFLP and microsatellite genotypic data. From the 88 clonal isolates initially analyzed by AFLP and microsatellite genotyping, 11 isolates were excluded from the joint analysis of these markers. For two excluded isolates, PCR amplification failed in the AFLP amplification reactions, and nine isolates yielded scoreable amplification products for only half or fewer of the 18 microsatellite loci. The number of alleles per locus and of unique multilocus genotypes was assessed separately for the AFLP and microsatellite data sets of the remaining 77 isolates using the software Arlequin Ver. 2.0 (http://cmpg. unibe.ch/software/arlequin/). As a measure for the capacity of gene loci to detect genetically differentiated individuals, gene diversity for each microsatellite and AFLP locus was estimated using the program LIAN (Haubold and Hudson 2000) after the formula for $\hat{H}$ (Nei 1987) through the Web interface of Version 3.5 (http://adenine.biz.fh-weihenstephan.de/cgi-bin/ lian/lian.cgi.pl). The value of $\hat{H}$ has a minimum of 0 (in the case of an uninformative locus with only one allele) and approximates 1 for the most informative loci (i.e., loci with many alleles at equally low frequency). For biallelic AFLP loci, the maximum value, however, is $\sim 0.5$.

The pair-wise similarities of microsatellite and AFLP genotypes were calculated separately using BioNumerics v2.50 (Applied Maths, Sint-Martens-Latem, Belgium) statistical software according to the Dice and the Simple Match index of similarity, respectively (for a review on appropriate similarity indices for different genotypic markers, see Kosman and 
Leonard 2005). The unweighted pair group method with arithmetic mean (UPGMA) dendrograms were constructed using the same software. Two different resampling approaches were adopted for each marker to obtain an independent measure of the reproducibility of the arrangement of individuals in the dendrograms. The dependence of the results on the number of loci was tested at the same time. To check the degree of consistency of pair-wise dissimilarity matrices obtained with different markers and numbers of loci, two arbitrary, nonoverlapping subsets of loci were sampled from all loci from the AFLP and microsatellite data with 10 and three loci, respectively. Then pair-wise Dice or Simple Match dissimilarities were calculated for each subset, and a Mantel test (Mantel 1967) was performed on the resulting dissimilarity matrices by the Pearson product-momentum correlation. The procedure was repeated 50 times, and the average correlation coefficients and significances were obtained. The number of markers included in the bootstrapped subsets was then stepwise raised by five loci for AFLP and one locus for microsatellites, until 240 and nine loci were reached, respectively. The second approach, which corresponds to that developed by King et al. (1993) and Tivang et al. (1994), also involved bootstrapping of subsets of different numbers of loci for each marker. Here, 100 subsets of a certain number of AFLP or microsatellite loci were arbitrarily sampled from all loci, and pair-wise Simple Match or Dice dissimilarities were calculated for each subset of AFLP or microsatellite loci, respectively. The average coefficient of variation $(\mathrm{CV})$ was calculated from all pair-wise distances. The markers included in the bootstrapped sets of loci were increased stepwise for AFLP and microsatellite subsets by 10 and one loci, starting with 11 and two loci per bootstrapped subset, respectively, until subsets were as large as the total number of AFLP and microsatellite loci. A linear regression was then calculated with log-transformed numbers of loci and mean $\mathrm{CV}$ values for each number of loci used in the bootstrap procedure. The number of loci needed to reach $\mathrm{CV}$ values of 0.1 and 0.05 were estimated by inter- or extrapolation using the regression function. All bootstrap procedures and regression analyses were performed in the statistical software package $R(R$ Development Core Team 2007); the R functions with example data and usage instructions are available for download (http:/ / epic.awi.de/epic/Main?puid=33416).

Qualitative and quantitative analysis of PSP toxins. Batch cultures of all 88 clonal $A$. tamarense isolates were grown in $50 \mathrm{~mL}$ cell culture flasks and harvested by centrifugation as for DNA extraction when cultures were in early to midexponential growth phase (at $\sim 1.5$ to $4 \times 10^{6}$ cells $\cdot \mathrm{L}^{-1}$ ). One $\mathrm{mL}$ of the same cultures was fixed with Lugol's iodine solution, and later cells were counted on an Axiovert (Zeiss, Jena, Germany) inverted microscope.

Toxin analysis was performed by automated reverse-phase HPLC, applying ion-pair chromatographic separation, followed by postcolumn oxidation with periodic acid and fluorescence detection, based on the method of Thielert et al. (1991) modified with details by Hummert et al. (1997) and Yu et al. (1998). The sample preparation protocol of Hummert et al. (1997) was followed for extraction of PSP toxins from the frozen cell pellets by addition of $1 \mathrm{~mL} 0.03 \mathrm{~N}$ acetic acid to each pellet and sonication of cells. The $0.45 \mu \mathrm{m}$ PTFE-filtered acetic-acid cell lysates were injected into an HPLC system consisting of an SIL-10A intelligent autosampler, an LC-10ATvp intelligent pump, an SCL-10Avp system controller, a $1 \mathrm{~mL}$ CRX400 postcolumn reaction unit (Pickering Laboratories, Mountain View, CA, USA), two LC-9A pumps for delivery of postcolumn reaction solutions, and an RF-10Axl fluorescence detector (all Shimadzu, Duisburg, Germany). The $N$-sulfocarbamoyl toxins were indirectly determined after hydrochloricacid-mediated hydrolysis by determining the ratios of the difference in peak areas to those obtained directly from the original acetic-acid extract. Toxin standards were obtained from the CRMP, Institute for Marine Biosciences, National Research Council, Halifax, Canada. A standard for dcSTX was provided by the European Commission (BCR, Community Bureau of Reference), Brussels, Belgium.

The total PSP-toxin cell quota, as well as the cellular content of the different derivatives, was calculated from molar concentrations after estimation of cell numbers from the Lugol's fixed samples. Tandem mass-spectrometry was performed to confirm directly the presence of $N$-sulfocarbamoyl toxins in unhydrolyzed samples as described in Krock et al. (2007). Molar quantities of the epimeric pairs C1/C2, GTX2/GTX3, GTX1/GTX4 were fused in subsequent analyses because of the known facile epimerization during storage and processing (Hall et al. 1990). A cluster analysis of toxin profiles was performed after calculation of the Euclidean distances among all pairs of isolates. To weight all toxin groups equally, the molar percentages of each toxin group in each isolate were expressed as a proportion of the highest molar percentage for the respective toxin group within all isolates (Cembella et al. 1987). Calculations of pair-wise distances and construction of a UPGMA dendrogram were performed using BioNumerics v2.50 (Applied Maths). Chauvenet's criterion $(P<0.05)$ and the Shapiro-Wilk $W$-test in STATISTICA ${ }^{\mathrm{TM}}$ V.6 (StatSoft ${ }^{\circledR}$, Hamburg, Germany) were used to determine if potential outliers in the data on PSP-toxin content $\left(\mathrm{fmol} \cdot \mathrm{cell}^{-1}\right)$ of $A$. tamarense isolates could be identified and to determine if the data were normally distributed, respectively.

Allelochemical activity of A. tamarense isolates. The allelochemical and lytic activity of 67 clonal $A$. tamarense isolates was tested in two series of experiments against different target organisms, the cryptophyte $R$. salina and the dinoflagellate $O$. marina. Clonal isolates of $A$. tamarense were grown in batch cultures as described herein until they reached midexponential growth phase. After estimation of cell concentrations of A. tamarense by counting Lugol's iodine fixed cells within a subsample that contained at least 400 cells, the batch cultures were diluted with $\mathrm{K}$ medium to a final cell concentration of 1,500 cells $\cdot \mathrm{mL}^{-1}$. Then $15 \mathrm{~mL}$ of diluted cultures was dispensed into triplicate $20 \mathrm{~mL}$ scintillation glass vials. Each replicate was spiked with a dense culture of $R$. salina to a final concentration of $10 \times 10^{4}$ cells $\cdot \mathrm{mL}^{-1}$. The test vials were then incubated under the same culture conditions as described.

Two negative and one positive control were performed in the same way as the experimental assays. The first negative control contained only $15 \mathrm{~mL}$ of $\mathrm{K}$ medium, whereas the second negative control was spiked with $15 \mathrm{~mL}$ of a batch culture of the nontoxic dinoflagellate Scrippsiella trochoidea (F. Stein) Balech ex A. R. Loebl. (final cell concentration $1.5 \times 10^{3}$ cells $\left.\cdot \mathrm{mL}^{-1}\right)$. The positive control was produced by adding $15 \mathrm{~mL}$ of a culture of the allelochemically active A. tamarense strain SZNB01 (Tillmann and John 2002), established by M. Montresor from the Gulf of Naples (final cell concentration of $1.5 \times 10^{3}$ cells $\left.\cdot \mathrm{mL}^{-1}\right)$. After $24 \mathrm{~h}\left(\mathrm{~T}_{24}\right)$, cells of A. tamarense and $R$. salina were fixed with $0.3 \mathrm{~mL}$ Lugol's iodine solution, and concentrations of intact cells of both species were determined under an inverted microscope.

For the second experimental series, $200 \mu \mathrm{L}$ of diluted A. tamarense cultures was dispensed in triplicate to wells of a 96-well cell culture plate (TPP). Each replicate was spiked with $10 \mu \mathrm{L} \mathrm{O.} \mathrm{marina} \mathrm{culture}\left(\right.$ at $\sim 1 \times 10^{4}$ cells $\left.\cdot \mathrm{mL}^{-1}\right)$ to obtain a final density of $O$. marina of $\sim 500$ cells $\cdot \mathrm{mL}^{-1}$. Two negative and one positive control were performed in the same way as for the experiments with $R$. salina. After $24 \mathrm{~h}$, cells of A. tamarense and $O$. marina were fixed by addition of $5 \mu \mathrm{L}$ Lugol's iodine solution, and the concentration of intact cells was enumerated with an inverted microscope.

The magnitude of the lytic effects of each A. tamarense isolate was expressed by calculating the fraction of intact cells versus 
the average cell number of the respective controls after $24 \mathrm{~h}$. The Shapiro-Wilk $W$-test in STATISTICA ${ }^{\mathrm{TM}}$ V.6 (StatSoft ${ }^{\circledR}$ ) was used to determine if the data on allelochemical properties of $A$. tamarense isolates against $O$. marina $\left(\% \mathrm{~T}_{24}\right)$ were normally distributed.

Statistical analyses for correlations among different markers. Matrices of pair-wise similarities among individuals used for the construction of UPGMA dendrograms with the data sets from AFLP, microsatellite, and PSP analyses were subjected to Mantel tests (Mantel 1967) with 9,999 permutations using the statistical software package Brodgar Ver. 2.5.0 (Highland Statistics Ltd., Newsburgh, UK). Pearson product-momentum correlation was analyzed to determine the degree of correlation between different marker data sets.

The association of certain AFLP markers with total cellular PSP-toxin content and the allelochemical potency were analyzed by multiple Student's $t$-tests in Excel software (Microsoft, Redmond, WA, USA). Data sets included phenotypic and genotypic data from 86 and 67 isolates in the case of PSP-toxin content and allelochemical properties toward $O$. marina, respectively. Clonal isolates were grouped for each AFLP locus according to the presence or absence of an amplified band for this specific locus. Student's $t$-tests between the resulting presence and absence groups were performed for all AFLP loci for which the number of isolates assigned to either group was at least 10, yielding 301 and 265 tests of association of AFLP loci with PSP-toxin content and allelochemical activity, respectively. $P$-values were adjusted by Bonferroni correction to account for the number of tests.

\section{RESULTS}

AFLP genotypic data and analysis. The four combinations of primers in the AFLP amplification reactions produced a total of 482 well-scoreable PCR products of distinct size (i.e., presence alleles) in the 77 clonal isolates of the combined AFLP-microsatellite data set. The number of AFLP loci per primer pair ranged from 109 to 133, with an average number of 120.5 $(\mathrm{SD} \pm 8.8)$ (Table 1$)$. Gene diversity $(\hat{H})$ at AFLP loci ranged from 0.03 to 0.51 , while the mean gene diversity was estimated as $\hat{H}=0.27(\mathrm{SE} \pm 0.007)$. Comparison of binary AFLP profiles showed no identical multilocus AFLP genotype within the group of 77 isolates. The UPGMA dendrogram based on Simple Match similarities of all pairs of isolates (Fig. la) showed that average branch length ranged from $65 \%$ to $70 \%$, but clearly separated clusters were not formed.

Correlations of similarity matrices derived from subsets of AFLP loci as tested by Mantel tests were always highly significant $(P<0.001)$ when subsets included 45 or more arbitrarily selected AFLP loci. The correlation coefficients increased rapidly until subsets included $\sim 225$ AFLP loci but then tended to increase only slightly as more AFLP loci were included (Fig. 2). The highest correlation coefficient was observed for subsets that included the maximum number of AFLP loci. When only up to nine AFLP loci were included in the subsets, correlation coefficients were always low and rarely significant at $P<0.01$ (Fig. 3a). Analysis of coefficients of variation $(\mathrm{CV})$ of pair-wise genetic similarities by bootstrapped subsets with increasing number of AFLP loci resulted in a steep decline of CV values for the smaller subsets with each additional locus included. The threshold value of a $\mathrm{CV}$ of 0.1 was already reached with $\sim 270$ loci, and the largest AFLP data set analyzed, including 481 of the 482 sampled loci, resulted in a CV of 0.075 (Fig. 4). Extrapolating the linear regression function beyond the range of AFLP loci assessed in this study provided an estimate that $\sim 1,080$ loci would yield a $\mathrm{CV}$ of 0.05 .

Microsatellites. The genotypes obtained by microsatellite analysis were very diverse. No identical multilocus genotype was found among the 77 clonal isolates of $A$. tamarense. The number of alleles for a specific microsatellite marker varied considerably and ranged from two to 10 (Table 2), with an average of $5.5(\mathrm{SD} \pm 2.3)$. Gene diversity among microsatellite loci also varied and ranged from 0.31 to 0.83 (Table 2 ). The mean gene diversity over all microsatellite loci was $\hat{H}=0.62$ $(\mathrm{SE} \pm 0.036)$. The cluster analysis of clonal A. tamarense isolates based on the pair-wise Dice similarity index of microsatellite genotypes did not allow identification of separated subgroups within the population (Fig. 1b).

The correlation among the subgroups as tested by Mantel tests performed on the similarity matrices obtained for the subgroups was never significant (Fig. 3b), when arbitrarily composed subsets of nine microsatellite markers were each taken to evaluate the consistency of genetic similarities among isolates. The mean correlation coefficient obtained for nine microsatellite loci was 0.09 , comparable to the degree of correlation obtained with about the same number of AFLP loci in this study (Fig. 3a). The analysis of CV of pair-wise genetic similarities by bootstrapped subsets with an increasing number of microsatellite loci yielded a steep decline in mean $\mathrm{CV}$ values for the larger subsets with each additional locus included. The lowest mean CV $(\sim 0.2)$ was reached with the largest bootstrapped subset (18 loci). Analysis of the AFLP data set yielded a comparatively low mean CV only when at least 70 loci were included in the bootstrapped subsets. However, the threshold $\mathrm{CV}$ value of 0.1 was not reached with 18 microsatellite loci (Fig. 4). Extrapolating the linear regression function beyond the range of microsatellite loci assessed in this study allowed an estimate that $\sim 58$ and 224 microsatellite loci would yield CV values of 0.1 and 0.05 , respectively.

Variation in PSP toxins. The clonal isolates showed a remarkable variation with respect to both toxin content per cell and the relative amount of the different toxin derivatives, expressed as the toxin profile characteristic for individual isolates (Fig. 5b). Data on cellular toxin content were normally distributed when the two extreme values (471.1 and 428.9 $\mathrm{fmol} \cdot \mathrm{cell}^{-1}$ ) were excluded from the test for normal distribution according to Chauvenet's criterion 
a)

\section{Simple Match coefficient (\%similarity)}

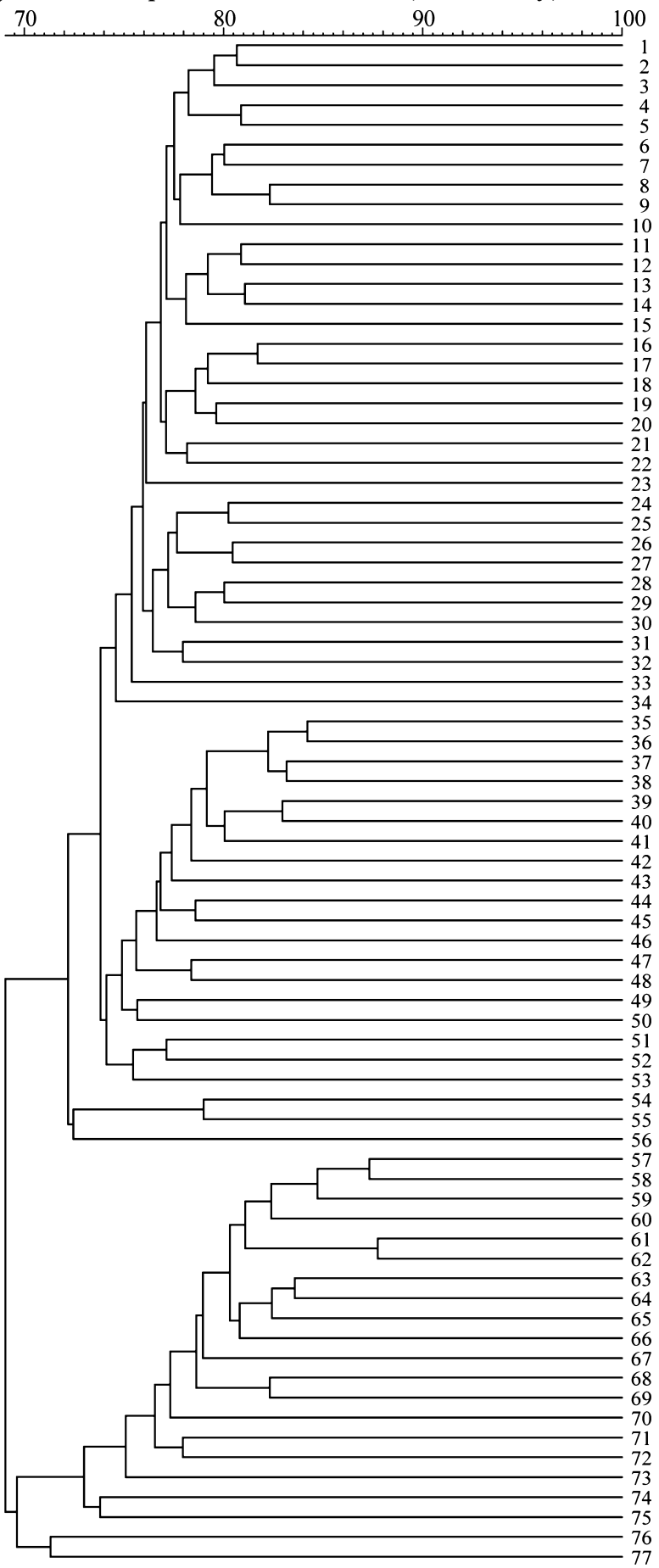

b)

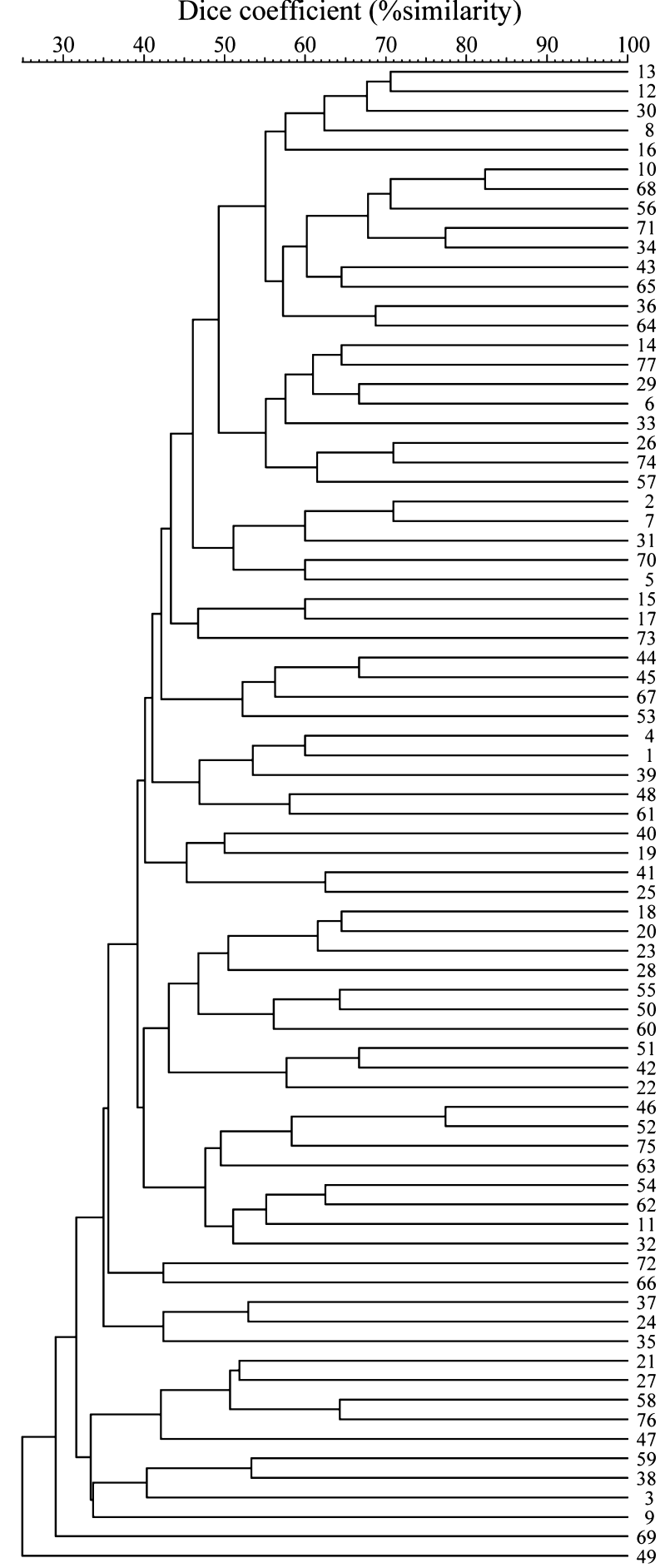

FIG. 1. UPGMA dendrograms of multilocus genotypes based on the Simple Match coefficient of similarity for amplified fragment length polymorphism (AFLP) data (a) and on the Dice coefficient of similarity for microsatellite data (b). Alexandrium tamarense isolates from the North Sea are numbered from 1 to 77, according to their order in the dendrogram obtained by AFLP data. UPGMA, unweighted pair group method with arithmetic mean.

(Taylor 1997) and ranged from 25.3 to $367.7 \mathrm{fmol} \cdot$ cell $^{-1}$. The mean PSP-toxin cell quota for the A. tamarense isolates was $165.2 \mathrm{fmol} \cdot \mathrm{cell}^{-1}(\mathrm{SD} \pm$ $85.4 ; n=88$ ). Plotting the data not only showed that values were continuously distributed with a distinct maximum but also displayed skewness toward high toxin content (data not shown). Neosaxitoxin (NEO) was on average the most abundant of all PSP toxins and reached the highest molar percentages. The epimers $\mathrm{C} 1 / \mathrm{C} 2$ were the second most 


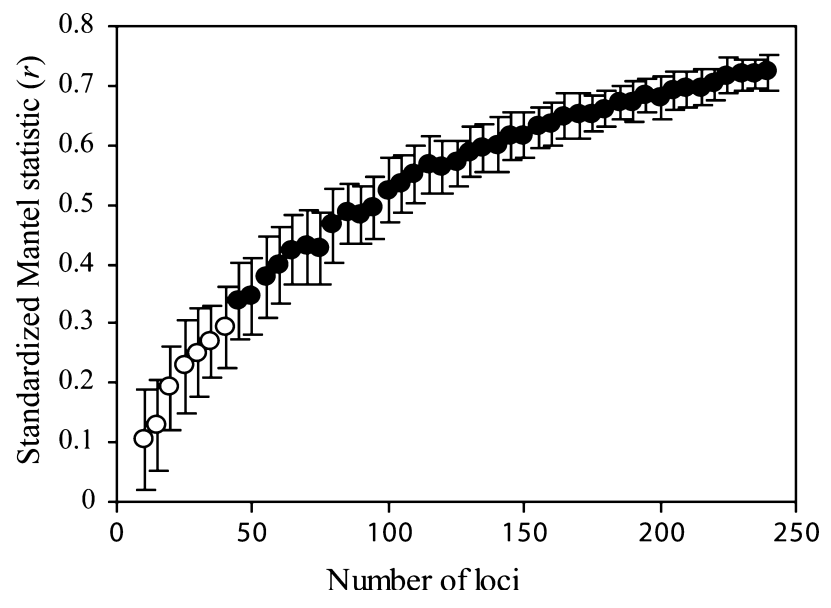

FIG. 2. Standardized statistic of Mantel tests $(r)$ versus number of loci that were contained in each bootstrapped subset $( \pm \mathrm{SD})$ for amplified fragment length polymorphism (AFLP) data. Black circles symbolize significant values at $P<0.01$.

prominent toxin group, followed by saxitoxin (STX). The residual toxins, GTX1/GTX4, GTX2/ GTX3, B1, and B2, contributed on average $<10 \mathrm{~mol} \%$ to the PSP-toxin composition, but in some isolates, these toxins contributed relatively much more (e.g., maximum values for GTX2/GTX3 almost reached those of NEO, Table 3 ).

Neither decarbamoyl NEO (dc-NEO) nor any decarbamoyl gonyautoxins (dc-GTX1/dc-GTX4 and dc-GTX2/dc-GTX3) were detected, but traces of dc-STX were present in some isolates to a maximum of $0.6 \mathrm{~mol} \%$ of total toxin and an average of $0.12 \mathrm{~mol} \%$ ( $\mathrm{SD} \pm 0.13)$. Small amounts of dc-STX found in Alexandrium may be due either to its presence as a transient biosynthetic intermediate or as an artifact resulting from decarbamoylization of either STX or B1. This component was therefore excluded from further analyses in a conservative approach because further analyses were based on toxin profiles equally weighted to the different toxin groups.

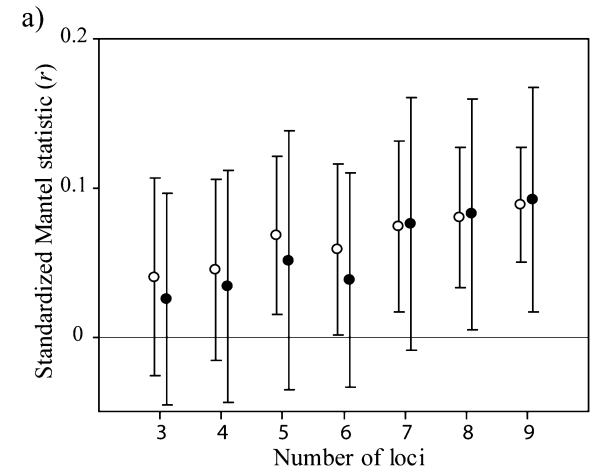

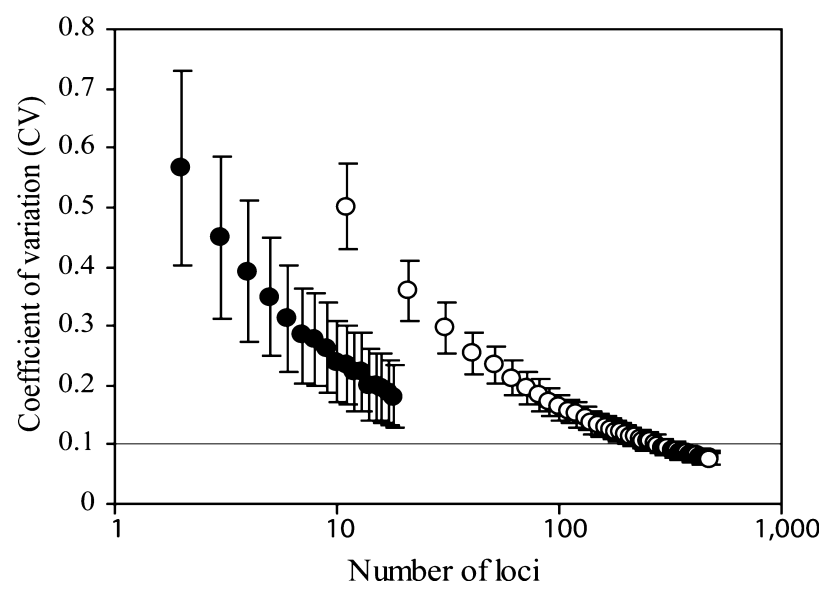

FIg. 4. Average coefficient of variation (CV) versus number of loci in bootstrapped subsets $\left({ }_{ \pm} \mathrm{SD}\right)$ for microsatellite data (filled circles) and amplified fragment length polymorphism (AFLP) data (open circles). The $x$-axis is scaled logarithmically.

Variation in allelochemical activity. The allelochemical potency of $A$. tamarense isolates against $R$. salina, expressed as percent of target cells in treatment related to the number of target cells in the negative control without dinoflagellate cells $\left(\% \mathrm{~T}_{24}\right)$, ranged from 0 to 55.5. Interestingly, only two isolates of $A$. tamarense did not cause severe damage to $R$. salina target cells (Fig. 6). In the control treatments, the positive control with $A$. tamarense strain SZNB01 caused complete lysis of $R$. salina cells, whereas the negative control treatment with $S$. trochoidea did not cause a significant reduction in $R$. salina cell numbers (Fig. 6).

Against $O$. marina, allelochemical activity of A. tamarense $\left(\% \mathrm{~T}_{24}\right)$ ranged from 1.2 to 100.9 , with a mean value of $48.3(\mathrm{SD} \pm 24.6)$. The allelochemical properties against $O$. marina $\left(\% \mathrm{~T}_{24}\right)$ among the 67 A. tamarense isolates were confirmed to be normally distributed.

Statistical analyses for correlations among different markers. The Mantel tests on the similarity matrices obtained

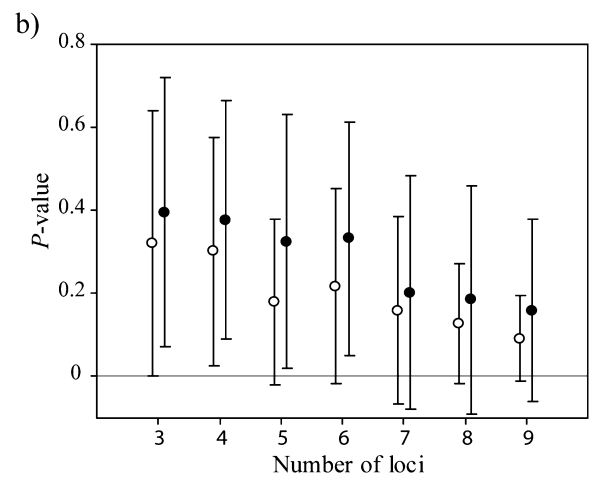

FIG. 3. (a) Standardized statistic of Mantel tests $(r)$ versus number of loci that were contained in bootstrapped subsets (mean \pm SD) for microsatellite data (open circles) and amplified fragment length polymorphism (AFLP) data (filled circles) and (b) the corresponding $P$-values of 50 replicates $($ mean $\pm \mathrm{SD})$. 
a)

\section{Scaled Euclidean distance (\%similarity)}

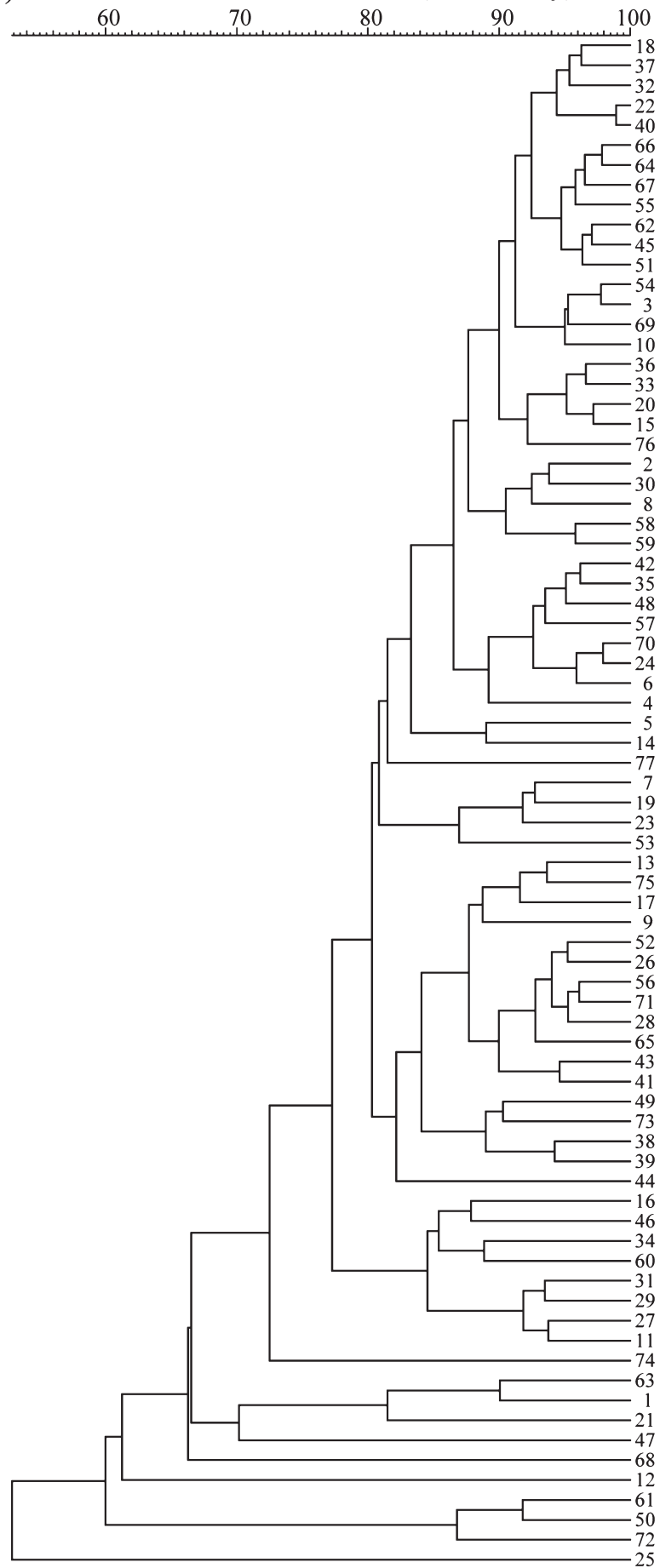

b) PSP (mol\%)

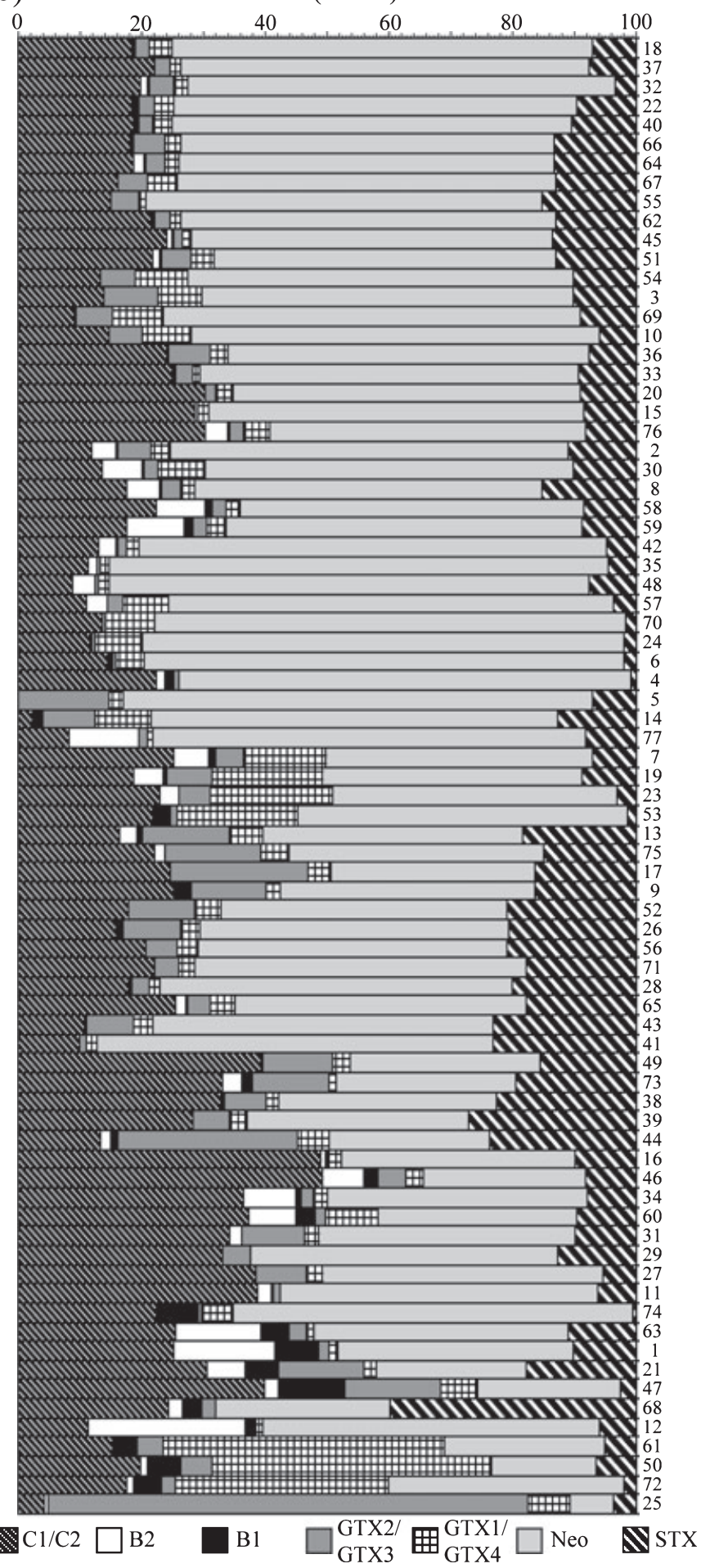

FIG. 5. UPGMA dendrogram of PSP-toxin profiles based on the Euclidean distance calculated for the relative molar composition of toxins (a) and respective toxin profiles in mol\% (b) of all genotyped isolates from the North Sea population. Alexandrium tamarense isolates from the North Sea are numbered as in Figures 1 and 6. Distance is scaled in percent of the maximum distance among characters in the data set and converted to percent similarity $(100-$ scaled Euclidean distance $=\%$ similarity $)$. PSP, paralytic shellfish poisoning; UPGMA, unweighted pair group method with arithmetic mean.

by the genotypic markers (AFLP and microsatellites) and PSP-toxin profiles as a phenotypic character did not show significant $(P<0.05)$ correlation. The two genotypic markers, however, exhibited weakly $(r=0.12)$ but significantly $(P<0.005)$ correlated similarity matrices. 
TABLE 3. Range and mean $( \pm \mathrm{SD})$ of the cellular content of PSP toxins (in $\mathrm{fmol} \cdot \mathrm{cell}^{-1}$ ) and the relative contribution of analogs to the toxin composition of 88 clonal isolates of Alexandrium tamarense.

\begin{tabular}{llccc}
\hline \hline Toxin & $\begin{array}{c}\text { Cellular } \\
\text { content }\end{array}$ & Mean & Mol \% & Mean \\
\hline STX & $0.2-67.0$ & $18.5( \pm 14.3)$ & $0.3-39.6$ & $11.1( \pm 6.9)$ \\
NEO & $6.8-359.1$ & $89.5( \pm 61.6)$ & $7.2-80.8$ & $52.5( \pm 15.9)$ \\
GTX1/GTX4 & $0.0-99.5$ & $9.3( \pm 16.3)$ & $0.0-45.7$ & $5.4( \pm 7.9)$ \\
GTX2/GTX3 & $0.0-73.6$ & $8.6( \pm 10.6)$ & $0.0-77.8$ & $6.0( \pm 9.2)$ \\
B1 & $0.0-13.4$ & $1.8( \pm 3.0)$ & $0.0-11.1$ & $1.2( \pm 2.0)$ \\
B2 & $0.0-93.2$ & $4.9( \pm 11.9)$ & $0.0-25.3$ & $2.4( \pm 4.3)$ \\
C1/C2 & $0.0-89.8$ & $32.6( \pm 18.3)$ & $0.0-49.4$ & $21.4( \pm 9.6)$ \\
\hline
\end{tabular}

PSP, paralytic shellfish poisoning.

The multiple $t$-tests performed to test the association of alleles at certain AFLP loci with either the cellular PSP-toxin content of clonal A. tamarense isolates or their allelochemical activity against $O$. marina did not show any significant association $(P<0.05)$ between any of the polymorphic AFLP loci and either of the two phenotypic characters. The lowest $P$-value $(P=0.00018)$ for the pair-wise $t$-tests for association of cellular PSP-toxin content with any of the AFLP loci, however, almost met the Bonferroni corrected significance limit of $5 \% \quad(P=0.00017$; $n=301)$.

\section{DISCUSSION}

The nature of genotypic population markers. In our study, the two markers (AFLP and microsatellites) did not give concordant patterns of genetic relatedness among the individual clones from the North Sea population, although matrices of pair-wise similarities obtained for both markers were significantly correlated (Mantel test) at a very low level. A plausible explanation for this apparent mismatch of pair-wise genetic relatedness derives from testing the congruence of bootstrapped subsets of each genotypic marker with independent subsets of the same marker. Whereas pair-wise similarity matrices of subsets of AFLP loci always reached significant correlations for subsets with 45 or more loci, the missing significance and low correlation indices of the largest subsets of microsatellite markers (nine loci in each subset) indicated that the representation of genetic relatedness of isolates by this marker with the number of loci in this study is not stable. The high number of available AFLP markers and the high degree of correlation for those subsets that contained only half the AFLP loci analyzed in this study (see Fig. 2) indicate that the pattern will stabilize further, as more markers are included. The set of AFLP loci are therefore better suited for the characterization of genotypic similarities of A. tamarense isolates than the microsatellites applied in the study. Bootstrap simulations of the CV showed that values for both genotypic markers tended to decrease rapidly, when only a few more marker loci were added to the subsets, but the CV for microsatellites did not reach the threshold of 0.1 . This value is generally expected to be the minimum for the generation of reliable patterns of pair-wise genetic relatedness among individuals (see Garcia et al. 2004 and references therein). However, the CV values for pair-wise genotypic dissimilarities obtained for bootstrapped microsatellite subsets decreased much faster with additional loci than for AFLP, generally interpreted as an indication of the higher resolving power of microsatellite loci. The higher resolution is most likely due to the predominantly multiallelic nature of microsatellites, when compared to biallelic AFLP markers, which also leads to higher average gene diversity in comparison to AFLP (Nybom 2004). The technical demands in obtaining a sufficiently high number of polymorphic microsatellites, however, hinder its usefulness for studies of intrapopulation differentiation, including apparently the present study of Alexandrium.

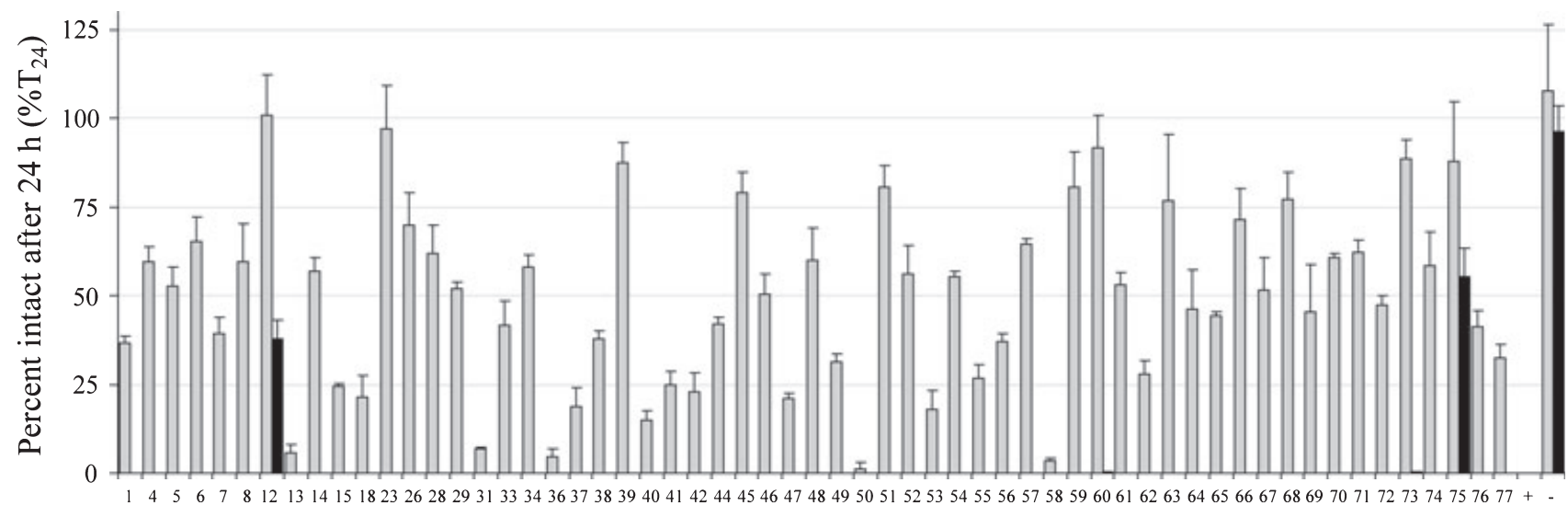

Fig. 6. Allelochemical effects of Alexandrium tamarense isolates toward Oxyrrhis marina (gray bars) and Rhodomonas sp. (black bars) as percentage of intact target cells after $24 \mathrm{~h}$ coincubation of intact cells in the negative control with $\mathrm{K}$ medium $\left(\% \mathrm{~T}_{24}\right)$. Identifiers of $A$. tamarense isolates correspond to those used in Figures 1 and 5. +: positive control for lytic effect by addition of A. tamarense strain SZNB01; -: negative control by addition of nonlytic Scrippsiella trochoidea. 
Significance of genotypic diversity within natural populations. In contrast to the present study in which we did not find repeated multilocus genotypes, other extensive surveys on genotypic composition of planktonic dinoflagellate populations (e.g., Shankle et al. 2004 and Nagai et al. 2007) and other phytoplankton species, such as diatoms (Rynearson and Armbrust 2000, Evans et al. 2005, Godhe et al. 2006), reported repeated sampling of genotypes. Theoretically, there is a high likelihood of eventually finding isolates of identical clonal origin in any such study on genotypic richness in predominantly clonally reproducing organisms, if only sample size were big enough (Halkett et al. 2005). The appearance of identical genotypes, however, does not necessarily reflect true clonal identity, since genotyping in previous studies relied on different types of genetic markers and/or numbers of loci. The chances of detecting multilocus genotypic differences in the North Sea population of A. tamarense, for which as many as 18 microsatellites and 482 polymorphic AFLP loci were used, were consequently higher than in previous studies that made use of less polymorphic loci. The repeated detection of certain genotypes in other studies might be the result of the lower differentiating capacity of the respective set of genotypic markers employed. Interestingly, the two most similar microsatellite genotypes from the North Sea population share the same alleles in 14 out of 18 microsatellite loci but carry different alleles at the residual four loci. This illustrates that a large set of polymorphic genotypic markers is needed to yield good resolution of genotypic richness in phytoplankton populations, if the aim of such a study is to gain insight into the genotypic diversity or the frequency of occurrence of clonal individuals.

With respect to the supposition that the genetic diversity in a population reflects its potential to adapt to changing environments (Fisher 1930, Barrett and Schluter 2008), the discovered high genetic diversity in the population of $A$. tamarense indicates that it is well prepared to withstand frequent changes in environmental conditions. The number of possible combinations of microsatellite and AFLP alleles due to recombination should be enormously high. The theoretically possible number of AFLP genotypes $\left(1.25 \times 10^{145}\right.$ with 482 binary loci $)$ exceeds by far the number of $A$. tamarense cells that could be present within a given spatial-temporal frame in any natural planktonic population-even in blooms of high cell concentrations $\left(>1 \times 10^{6}\right.$ cells $\left.\cdot \mathrm{L}^{-1}\right)$. Taking the estimates of gene diversity as the probability of sampling different alleles at a specific locus, one minus the gene diversity is the probability of sampling the same allele at a locus. Hence, the product of the latter estimates from all loci yields the probability of sampling the same multilocus genotype at the given allele frequencies, namely, $8.9 \times 10^{-9}$ for microsatellites and $5.2 \times$
$10^{-73}$ for AFLP. The number of both molecular markers, applied in this study, therefore, would suffice to reveal clonal identity with high certainty, if identical multilocus genotypes were found in several isolates.

Both molecular markers employed in this study of A. tamarense are assumed to be neutral with respect to phenotypic variation among the clonal isolates. Yet, the high genotypic and clonal diversity that they reveal raises speculation that this diversity also reflects broad phenotypic variation caused by variation in genes involved in the expression of these phenotypic traits.

PSP-toxin content and profile variation. The diverse set of toxin profiles from this North Sea population is, with a few exceptions, characterized by very small transitions in the proportions of PSP toxins. Consequently, the toxin profiles among subclusters vary rather little within the next higher hierarchical cluster (Fig. 5a). The small differences between cluster hierarchies suggest no clear separation of toxin profiles into discrete groups. The observation that certain derivatives or groups of toxins, such as NEO and $\mathrm{C} 1 / \mathrm{C} 2$ in our samples, dominate the toxin profiles of most isolates from a certain geographic region has been made in previous studies (e.g., Cembella et al. 1987, Anderson et al. 1994, Cembella and Destombe 1996).

Cellular toxin content, however, is a less stable phenotypic character of a clonal isolate than the relative composition of PSP toxins, which changes significantly only under rather extreme differences in growth conditions in batch and semicontinuous cultures (Boczar et al. 1988, Anderson et al. 1990). Direct comparison of the toxin content of A. tamarense isolates analyzed in this study with that of clonal isolates from other studies is therefore not advisable because of differences in culture conditions, sampling point along the growth curve, and toxin analytical methodologies. Time-series differences in cellular toxin content within nutrientreplete batch cultures of Alexandrium are typically less than 2-fold (Boczar et al. 1988 and Kim et al. 2005), but much larger differences are expressed under stress conditions, such as nutrient limitation (Boyer et al. 1987). The clonal isolates in our study were cultured simultaneously under standardized nutrient-replete conditions and harvested in exponential growth phase. The drastic differences in cellular toxin content of more than one order of magnitude found among the clonal isolates from the North Sea, therefore, probably represent real clonal differences among isolates and are not simply time- or condition-dependent culture artifacts.

The within-population variation in cellular PSP-toxin content found among the isolates from the North Sea corresponds well to values reported for clonal isolates from populations of $A$. tamarensel fundyense (North American ribotype/Group I) from the western North Atlantic (Cembella and Destombe 
1996) as well as the eastern (Cembella et al. 1987) and the western North Pacific (Yoshida et al. 2001). Our conclusion that high variation in cellular PSPtoxin content is a general feature of natural A. tamarense (Group I) populations, therefore, is in good agreement with other studies (Cembella et al. 1987, Kim et al. 1993, Anderson et al. 1994, Cembella and Destombe 1996, Yoshida et al. 2001).

Variation in allelochemical activity. The unexpectedly high level of phenotypic variation in allelochemical properties of $A$. tamarense is similar to the high diversity in PSP-toxin profiles and content among Alexandrium isolates. Allelochemical activity in Alexandrium spp. has previously been shown to be independent of PSP toxins (Tillmann and John 2002). Furthermore, the potency of allelochemical effects does not seem to be influenced by associated bacteria (Tillmann et al. 2008), nor is it altered detectably in clonal isolates after maintenance in culture for years (U. Tillmann, unpublished data). We therefore suggest that the differences in allelopathic characteristics are genetically fixed.

The results support the conclusion that $R$. salina is in general far more susceptible to the deleterious effects of $A$. tamarense allelochemicals than $O$. marina. This observation is in congruence with observations made with single strains from several species of the genus Alexandrium, for which the effect on $R$. salina was always higher than that on $O$. marina (Tillmann et al. 2008). As in other toxicity assays, percent lysis of target cells is a function of the dose (A. tamarense cell concentration), typically following a sigmoid dose-response curve (Tillmann et al. 2008). In the present experiments, recording full dose-response curves was not feasible because of the large number of clones tested. In the case of $R$. salina, the one fixed A. tamarense cell concentration applied in the bioassay $\left(1,500\right.$ cells $\left.\cdot \mathrm{mL}^{-1}\right)$ was obviously too high to resolve quantitative differences among the strains. However, due to the lower sensitivity of $O$. marina, the identical A. tamarense cell concentration was within the optimal range for this target to resolve quantitative differences among clones. It is important to note that among these 67 clones, only two isolates did not cause severe damage to $R$. salina target cells. This finding indicates that although there are large quantitative differences in the amount of lytic compounds produced among isolates, the absence of measurable lytic activity within A. tamarense clones is a rare exception.

Correlations between genotypic and phenotypic characteristics. Agreement of the similarity matrices for data on microsatellites and molar PSP-toxin composition was not expected, since the similarity matrix obtained for the microsatellite data did not stabilize in our test. In contrast, since AFLP provided reliable patterns of genotypic differentiation among individuals (clones) within the North Sea population, we assumed that if there was congruence between population-wide diversification based on molar toxin composition and either of the genotypic markers, AFLP would more likely reveal such a correlation. Nevertheless, the lack of congruence of populationwide similarity matrices for molar toxin composition and either genotypic marker (Mantel test) indicates that no global genotypic-phenotypic relationships are resolved for the North Sea population of A. tamarense. Since both molecular markers are generally assumed to be neutral with respect to phenotypic expression, a global correlation of this kind can be expected only under certain conditions. One such condition would be simultaneous differentiation of neutral markers and evolution of phenotypic differences according to an evolution by distance model.

Association of AFLP loci with phenotype expression. In this study, both phenotypic traits tested for association with individual AFLP loci-cellular PSP-toxin content and allelochemical activity-were normally distributed. Accordingly, they resemble quantitative traits, implying that several genes are involved in the expression of these phenotypes. Studies on the relation of phenotypic characteristics and genomic markers (e.g., by linkage analysis or association studies) can be expected to contribute substantially to the elucidation of the genetic basis of the development and maintenance of this phenotypic variation.

Our approach of testing for association of individual AFLP loci with the PSP toxin or allelochemical phenotype failed to show significant association between any of the genetic markers and either phenotype. Recombination of genes responsible for phenotypic expression is expected to occur frequently in outbreeding populations of Alexandrium. Few examples are reported where correlation of phenotypic traits and genetic markers have been detected in natural populations of closely related individuals (Erickson et al. 2004 and references therein). From a probabilistic perspective, the chances of detecting such associations are determined by several factors, such as genome size, the rate of genetic recombination around the phenotype-effective genes, the mutation rate at AFLP loci, as well as the number of individuals and AFLP loci included in the analysis. The probability of detecting phenotype-genotype associations might be very low in A. tamarense because the genome size is estimated at $\sim 200,000 \mathrm{Mb}$ in 143 chromosomes (D. L. Erdner and D. M. Anderson, unpublished data, cited in Hackett et al. 2005). However, evidence that the rate of recombination is similar to that in other eukaryotes is lacking, as the degree to which the genetic material is involved in meiotic recombination is unknown. In general, the number of AFLP loci required for screening to detect such functional linkage within natural, outbreeding populations is considerably higher than the number that allows for association analysis in experimental populations. Experimental crosses between allelochemically active and nonactive strains or between "high" and "low" PSP-toxin phenotypes, therefore, could facilitate the 
detection of functionally linked loci (Erickson et al. 2004).

The near significance of association of PSP-toxin content with one AFLP locus ( $t$-test, $P=0.053$ after Bonferroni correction) prompts the question of whether significant results may have been obtained by testing a moderately higher number of clones.

Implications of phenotypic variation on evolutionary ecology. The specific cause of the enormous phenotypic variation in allelochemical properties and PSPtoxin composition cannot be determined without definite knowledge of the ecological significance of the respective trait. The functional role of PSP toxins in the ecology and evolution of Alexandrium populations remains unknown (Cembella 2003), but if the expression of a high-toxicity phenotype was of evolutionary benefit to a certain clonal lineage, the question arises as to how lineages with low toxicity persist in the long run within natural populations. Directional selection would be expected to reduce the frequency of low-PSP-toxicity phenotypes. The production of a suite of secondary metabolites must also incur metabolic costs. In the absence of a selective advantage of a PSP-toxin phenotype, these costs, if high enough to diminish growth performance or other critical reproductive factors, must discriminate against the respective individual. This is the classic dilemma in the chemical ecology of secondary metabolites: balancing metabolic costs of production against evolutionary advantage.

The ecological significance of an allelopathic phenotype is believed to be reflected in its specific effects on certain target taxa (Tillmann and John 2002, Fistarol et al. 2004). Thus, by mediating a groupselective advantage, the presence of a number of allelochemically active Alexandrium clones could benefit the population as a whole. A reasonable explanation for the wide phenotypic variation in expression of this trait in the studied population is that allelochemical interactions among Alexandrium and its competitors and grazers only play an important role at certain stages of population development. Under this scenario, in phases of population development/growth when the selective pressure on weakly allelochemically active lineages is low due to the absence of sensitive grazers or competitors, expression of other phenotypic traits may be more critical. If certain phenotypic traits are of selective importance only for certain periods during population growth, balancing selection on other-at times more relevant-traits may lead to the maintenance of broad phenotypic diversity over time. The population-wide distribution of allelochemical activity suggests an important ecological role for this phenotype, although under the constraints at the time of sampling, a strong selective pressure on the respective phenotypic trait seems to be lacking. For the population under study, the stage of population development is not known, but future studies on the ecological significance of the allelopathic phenotype might benefit from directing a focus on allelochemically mediated species interaction during the cause of population and $\mathrm{HAB}$ development and maintenance.

\section{CONCLUSIONS}

We provide a comprehensive scenario of variation and diversity of phenotypic and genotypic characters of a large contemporaneous collection of clonal isolates representing a geographically defined population. The genotypic and phenotypic analysis tools applied here can clarify the ecological significance of these expressed characters in the context of population and bloom development, as well as to discover environmentally driven directional selection on the phenotype. To answer questions on the evolutionary benefit of certain phenotypic characters, such as biologically active secondary metabolites, detailed analyses of natural populations over longer time periods and larger-scale experiments (e.g., in mesocosms) in which environmental variables can be semicontrolled must be performed. Such studies will shed further light on the evolution of these traits in the marine dinoflagellate Alexandrium, as well as in other toxigenic eukaryotic microalgae responsible for HABs.

We would like to thank two anonymous reviewers and the editor for providing valuable comments on an earlier version of the manuscript. We also warmly thank E. Bresnan (Fisheries Research Institute, Aberdeen) and C. Schütt (AWI, BAH Helgoland) for their advice in sampling of $A$. tamarense populations in Scottish waters. We gratefully acknowledge K. Erler (Friedrich-Schiller University, Jena) for HPLC-FD analyses of PSP toxins, and B. Krock (AWI, Bremerhaven) for performing LC-MS analyses. M. Montresor (SZN, Naples, Italy) provided the A. tamarense strain SZNB01. Thanks to N. Jaeckisch for help in maintaining the algal cultures and to C. Hasemann and M. Freitag (all AWI, Bremerhaven) for contributions in preparing the manuscript. This work was funded by the Helmholtz Foundation of Research Centers (HGF) and is part of the HGF research program MARCOPOLI. Additional financial support was obtained by the research funding program LOEWE (Landes-Offensive zur Entwicklung Wissenschaftlich-ökonomischer Exzellenz) of Hesse's Ministry of Higher Education, Research, and the Arts.

Alpermann, T. J., Beszteri, B., Tillmann, U., Cembella, A. D. \& John, U. 2008. Species discrimination in the genus Alexandrium by amplified fragment length polymorphism. In Moestrup, $\varnothing$. [Ed.] Proceedings of the 12th International Conference on Harmful Algae. IOC (UNESCO), Copenhagen, Denmark, pp. 51-4.

Alpermann, T. J., John, U., Medlin, L. K., Edwards, K. J., Hayes, P. K. \& Evans, K. M. 2006. Six new microsatellite markers for the toxic marine dinoflagellate Alexandrium tamarense. Mol. Ecol. Notes 6:1057-9.

Anderson, D. M., Kulis, D. M., Doucette, G. J., Gallagher, J. C. \& Balech, E. 1994. Biogeography of toxic dinoflagellates in the genus Alexandrium from the northeastern United States and Canada. Mar. Biol. 120:467-78.

Anderson, D. M., Kulis, D. M., Sullivan, J. J. \& Hall, S. 1990. Toxin composition variations in one isolate of the dinoflagellate Alexandrium fundyense. Toxicon 28:885-93. 
Balech, E. 1995. The Genus Alexandrium Halim (Dinoflagellata). Sherkin Island Marine Station Publication, Sherkin Island, Co. Cork, Ireland, $151 \mathrm{pp}$.

Barrett, R. D. \& Schluter, D. 2008. Adaptation from standing genetic variation. Trends Ecol. Evol. 23:38-44.

Boczar, B. A., Beitler, M. K., Liston, J., Sullivan, J. J. \& Cattolico, R. A. 1988. Paralytic shellfish toxins in Protogonyaulax tamarensis and Protogonyaulax catenella in axenic culture. Plant Physiol. 88:1285-90.

Boyer, G. L., Sullivan, J. J., Andersen, R. J., Harrison, P. J. \& Taylor, F. J. R. 1987. Effects of nutrient limitation on toxin production and composition in the marine dinoflagellate Protogonyaulax tamarensis. Mar. Biol. 96:123-8.

Cembella, A. D. 2003. Chemical ecology of eukaryotic microalgae in marine ecosystems. Phycologia 42:420-47.

Cembella, A. D. \& Destombe, C. 1996. Genetic differentiation among Alexandrium populations from eastern Canada. In Yasumoto, T., Oshima, Y. \& Fukuyo, Y. [Eds.] Harmful and Toxic Algal Blooms. Intergovernmental Oceanographic Commission of UNESCO, Paris, pp. 447-50.

Cembella, A. D., Sullivan, J. J., Boyer, G. L., Taylor, F. J. R. \& Andersen, R. J. 1987. Variation in paralytic shellfish toxin composition within the Protogonyaulax tamarensis/catenella species complex; red tide dinoflagellates. Biochem. Syst. Ecol. 15:171-86.

Dahl, E., Lindahl, O., Paasche, E. \& Throndsen, J. 1989. The Chrysochromulina polylepis bloom in Scandinavian waters during spring 1988. In Cosper, E. M., Bricelj, V. M. \& Carpenter, E. J. [Eds.] Novel Phytoplankton Blooms: Causes and Impacts of Recurrent Brown Tides and Other Unusual Blooms. Springer Verlag, Berlin, pp. 383-405.

Erickson, D. L., Fenster, C. B., Stenoien, H. K. \& Price, D. 2004. Quantitative trait locus analyses and the study of evolutionary process. Mol. Ecol. 13:2505-22.

Evans, K. M., Kuhn, S. F. \& Hayes, P. K. 2005. High levels of genetic diversity and low levels of genetic differentiation in North Sea Pseudo-nitzschia pungens (Bacillariophyceae) populations. J. Phycol. 41:506-14.

Fisher, R. A. 1930. The Genetical Theory of Natural Selection, 1st ed. Oxford University Press, Oxford, UK, $318 \mathrm{pp}$.

Fistarol, G. O., Legrand, C., Selander, E., Hummert, C., Stolte, W. \& Granéli, E. 2004. Allelopathy in Alexandrium spp.: effect on a natural plankton community and on algal monocultures. Aquat. Microb. Ecol. 35:45-56.

Gallagher, J. C. 1980. Population genetics of Skeletonema costatum (Bacillariophyceae) in Narragansett Bay. J. Phycol. 16:464-74.

Gallagher, J. C. 1982. Physiological variation and electrophoretic banding patterns of genetically different seasonal populations of Skeletonema costatum (Bacillariophyceae). J. Phycol. 18:148-62.

Garcia, A. A. F., Benchimol, L. L., Barbosa, A. M. M., Geraldi, I. O., Souza, C. L., Jr. \& de Souza, A. P. 2004. Comparison of RAPD, RFLP, AFLP and SSR markers for diversity studies in tropical maize inbred lines. Genet. Mol. Biol. 27:579-88.

Godhe, A., McQuoid, M. R., Karunasagar, I., Karunasagar, I. \& Rehnstam-Holm, A.-S. 2006. Comparison of three common molecular tools for distinguishing among geographically separated clones of the diatom Skeletonema marinoi Sarno et Zingone (Bacillariophyceae). J. Phycol. 42:280-91.

Hackett, J., Scheetz, T., Yoon, H., Soares, M., Bonaldo, M., Casavant, T. \& Bhattacharya, D. 2005. Insights into a dinoflagellate genome through expressed sequence tag analysis. $B M C$ Genomics 6:80.

Halkett, F., Simon, J. C. \& Balloux, F. 2005. Tackling the population genetics of clonal and partially clonal organisms. Trends Ecol. Evol. 20:194-201.

Hall, S. 1982. Toxins and toxicity of Protogonyaulax from the Northeast Pacific. PhD dissertation, University of Alaska, Fairbanks, 196 pp.

Hall, S., Strichartz, G., Moczydlowski, E., Ravindran, A. \& Reichardt, P. B. 1990. The saxitoxins. Sources, chemistry and pharmacology. In Hall, S. \& Strichartz, G. [Eds.] Marine Toxins: Origin, Structure and Molecular Pharmacology. American Chemical Society Symposium Series 418, Washington, D.C., pp. 29-65.
Haubold, B. \& Hudson, R. R. 2000. LIAN 3.0: detecting linkage disequilibrium in multilocus data. Bioinformatics 16:847-8.

Hummert, C., Ritscher, M., Reinhardt, K. \& Luckas, B. 1997. Analysis of the characteristic PSP profiles of Pyrodinium bahamense and several strains of Alexandrium by HPLC based on ionpair chromatographic separation, post-column oxidation, and fluorescence detection. Chromatographia 45:312-6.

Ichimi, K., Suzuki, T. \& Ito, A. 2002. Variety of PSP toxin profiles in various culture strains of Alexandrium tamarense and change of toxin profile in natural A. tamarense population. J. Exp. Mar. Biol. Ecol. 273:51-60.

John, U., Fensome, R. A. \& Medlin, L. K. 2003. The application of a molecular clock based on molecular sequences and the fossil record to explain biogeographic distributions within the Alexandrium tamarense "species complex" (Dinophyceae). Mol. Biol. Evol. 20:1015-27.

John, U., Groben, R., Beszteri, B. \& Medlin, L. 2004. Utility of amplified fragment length polymorphisms (AFLP) to analyse genetic structures within the Alexandrium tamarense species complex. Protist 155:169-79.

Keller, M. D., Selvin, R. C., Claus, W. \& Guillard, R. R. L. 1987. Media for the culture of oceanic ultraphytoplankton. J. Phycol. 23:633-8.

Kim, C.-J., Kim, C.-H. \& Sako, Y. 2005. Paralytic shellfish poisoning toxin analysis of the genus Alexandrium (Dinophyceae) occurring in Korean coastal waters. Fish Sci. 71:1-11.

Kim, C. H., Sako, Y. \& Ishida, Y. 1993. Comparison of toxin composition between populations of Alexandrium spp. from geographical distant areas. Nippon Suisan Gakkaishi 59:641-6

King, G., Nienhuis, J. \& Hussey, C. 1993. Genetic similarity among ecotypes of Arabidopsis thaliana estimated by analysis of restriction fragment length polymorphisms. Theor. Appl. Genet. $86: 1028-32$.

Kooistra, W. H., Sarno, D., Balzano, S., Gu, H., Andersen, R. A. \& Zingone, A. 2008. Global diversity and biogeography of Skeletonema species (Bacillariophyta). Protist 159:177-93.

Kosman, E. \& Leonard, K. J. 2005. Similarity coefficients for molecular markers in studies of genetic relationships between individuals for haploid, diploid and polyploid species. Mol. Ecol. 14:415-24.

Krock, B., Seguel, C. G. \& Cembella, A. D. 2007. Toxin profile of Alexandrium catenella from the Chilean coast as determined by liquid chromatography with fluorescence detection and liquid chromatography coupled with tandem mass spectrometry. Harmful Algae 6:734-44.

Lilly, E. L., Halanych, K. M. \& Anderson, D. M. 2007. Species boundaries and global biogeography of the Alexandrium tamarense complex (Dinophyceae). J. Phycol. 43:1329-38.

Mantel, N. 1967. The detection of disease clustering and a generalized regression approach. Cancer Res. 27:209-20.

Medlin, L. K., Lange, M. \& Nothig, E. M. 2000. Genetic diversity in the marine phytoplankton: a review and a consideration of Antarctic phytoplankton. Antarct. Sci. 12:325-33.

Nagai, S., Lian, C., Hamaguchi, M., Matsuyama, Y., Itakaru, S. \& Hogetsu, T. 2004. Development of microsatellite markers in the toxic dinoflagellate Alexandrium tamarense (Dinophyceae). Mol. Ecol. Notes 4:83-5.

Nagai, S., Lian, C., Yamaguchi, S., Hamaguchi, M., Matsuyama, Y., Itakura, S., Shimada, H., et al. 2007. Microsatellite markers reveal population genetic structure of the toxic dinoflagellate Alexandrium tamarense (Dinophyceae) in Japanese coastal waters. J. Phycol. 43:43-54.

Nei, M. 1987. Molecular Evolutionary Genetics, 1st ed. Columbia University Press, New York, 512 pp.

Nybom, H. 2004. Comparison of different nuclear DNA markers for estimating intraspecific genetic diversity in plants. Mol. Ecol. $13: 1143-55$

Ogata, T., Ishimaru, T. \& Kodama, M. 1987. Effect of water temperature and light intensity on growth rate and toxicity change in Protogonyaulax tamarensis. Mar. Biol. 95:217-20.

R Development Core Team. 2007. R: A Language and Environment for Statistical Computing. R Foundation for Statistical 
Computing, Vienna, Austria. Available at: http://www.R-project.org (accessed 14 October 2009).

Rynearson, T. A. \& Armbrust, E. V. 2000. DNA fingerprinting reveals extensive genetic diversity in a field population of the centric diatom Ditylum brightwellii. Limnol. Oceanogr. 45:1329-40.

Sarno, D., Kooistra, W. H. C. F., Medlin, L. K., Percopo, I. \& Zingone, A. 2005. Diversity in the genus Skeletonema (Bacillariophyceae). II. An assessment of the taxonomy of $S$. costatumlike species with the description of four new species. J. Phycol. 41:151-76.

Scholin, C. A., Hallegraeff, G. M. \& Anderson, D. M. 1995. Molecular evolution of the Alexandrium tamarense 'species complex' (Dinophyceae): dispersal in the North American and West Pacific regions. Phycologia 34:472-85.

Scholin, C., Herzog, A. M., Sogin, M. \& Anderson, D. M. 1994. Identification of group- and strain-specific genetic markers for globally distributed Alexandrium (Dinophyceae). II. Sequence analysis of a fragment of the LSU rDNA gene. J. Phycol. 30:9991011.

Shankle, A. M., Mayali, X. \& Franks, P. J. S. 2004. Temporal patterns in population genetic diversity of Prorocentrum micans (Dinophyceae). J. Phycol. 40:239-47.

Smayda, T. J. 1997. Harmful algal blooms: their ecophysiology and general relevance to phytoplankton blooms in the sea. Limnol. Oceanogr. 42:1137-53.

Tautz, D. \& Renz, M. 1984. Simple sequences are ubiquitous repetitive components of eukaryotic genomes. Nucleic Acids Res. 12:4127-38.

Taylor, J. R. 1997. An Introduction to Error Analysis: The Study of Uncertainties in Physical Measurements. University Science Books, Sausalito, California, $327 \mathrm{pp}$
Thielert, G., Kaiser, I. \& Luckas, B. 1991. HPLC determination of PSP toxins. In Fremy, J. M. [Ed.] Proceedings of Symposium on Marine Biotoxins. Editions CNEVA, Maisons-Alfort, France, pp. 121-5.

Tillmann, U. 2004. Interactions between planktonic microalgae and protozoan grazers. J. Eukaryot. Microbiol. 51:156-68.

Tillmann, U., Alpermann, T., John, U. \& Cembella, A. D. 2008. Allelochemical interactions and short-term effects of the dinoflagellate Alexandrium on selected photoautotrophic and heterotrophic protists. Harmful Algae 7:52-64.

Tillmann, U. \& John, U. 2002. Toxic effects of Alexandrium spp. on heterotrophic dinoflagellates: an allelochemical defence mechanism independent of PSP-toxin content. Mar. Ecol. Prog. Ser. 230:47-58

Tillmann, U., John, U. \& Cembella, A. D. 2007. On the allelochemical potency of the marine dinoflagellate Alexandrium ostenfeldii against heterotrophic and autotrophic protists. J. Plankton Res. 29:527-43.

Tivang, J. G., Nienhuis, J. \& Smith, O. S. 1994. Estimation of sampling variance of molecular marker data using the bootstrap procedure. Theor. Appl. Genet. 89:259-64.

Vos, P., Hogers, R., Bleeker, M., Reijans, M., van de Lee, T., Hornes, M., Frijters, A., et al. 1995. AFLP: a new technique for DNA fingerprinting. Nucleic Acids Res. 23:4407-14.

Yoshida, T., Sako, Y. \& Uchida, A. 2001. Geographic differences in paralytic shellfish poisoning toxin profiles among Japanese populations of Alexandrium tamarense and A. catenella (Dinophyceae). Phycol. Res. 49:13-21.

Yu, R. C., Hummert, C., Luckas, B., Qian, P. Y., Li, J. \& Zhou, M. J. 1998. A modified HPLC method for analysis of PSP toxins in algae and shellfish from China. Chromatographia 48:671-6. 